\title{
Changing Perceptions of Pediatric Dental Practice during COVID Era
}

\author{
Faizal C Peedikayil ${ }^{1}$, Sruthi Chandran ${ }^{2}$, Nithya K ${ }^{3}$, Avaneeth Ram ${ }^{4}$
}

\begin{abstract}
Severe acute respiratory syndrome coronavirus 2 (SARS-CoV-2) emergence caused a global pandemic-coronavirus disease-2019 (COVID-19) and became one of the most important challenges to the healthcare profession. Adults are more infected while children also show mild clinical course. The risk of transmission of COVID-19 viruses is more for pediatric patients during dental treatments. Oral health prevention during COVID-19 pandemic plays a major role in pediatric patients. Through appropriate behavior management, pediatric dentists can minimize the probability of SARS-CoV-2 cross-infection. Proper care along with infection control strategies and newer approaches of management of children have to be incorporated in the pediatric dentistry after COVID-19 period.

Keywords: COVID-19, Cross-infection, Pandemic, Pediatric dentistry.

Journal of Oral Health and Community Dentistry (2021): 10.5005/jp-journals-10062-0105
\end{abstract}

\section{INTRODUCTION}

Severe acute respiratory syndrome coronavirus 2 (SARS-CoV-2) emergence causes a global pandemic called coronavirus disease2019 (COVID-19) and becomes one of the most important challenges to the healthcare profession. ${ }^{1}$ It affects individuals from all around the world. Studies showed that the virus has affected the pediatric population with milder symptoms to life-threatening complications. $^{2}$

First case of coronavirus was notified in the year 1960. Later in 2002 , it was treated as a noninfectious disease. In 2003, numerous cases of corona were reported in some countries. In 2012, several infected cases were reported in Saudi Arabia. The first case of current pandemic was reported in Wuhan, China, in December 2019. ${ }^{3}$ In India, COVID-19 cases were first reported on January 30, 2020 , with more than $1,000,000$ cases. Due to the spread of disease, World Health Organization (WHO) declared it as a global pandemic due to COVID-19 infection. Since the spread of disease variants of COVID-19 virus was reported by the WHO to the whole country. ${ }^{4,5}$

Coronavirus is a spherical single-stranded RNA virus covered with club-shaped glycoprotein. Alpha, beta, gamma, and delta are the four subtypes of coronavirus, and each subtype has many serotypes, in that some of them affect humans or other affected animals. ${ }^{3}$ COVID-19 is a novel beta coronavirus of the Coronaviridae family that causes a severe respiratory disease with a high fatality rate. ${ }^{6}$ The virus invades multiple respiratory epithelial cell types, monocytes, and alveolar macrophages by using the host angiotensin-converting Enzyme 2 (ACE2) receptors. Three days with a range of $0-24$ days is the estimated incubation period of this virus. ${ }^{2}$

Mode of transmission of coronavirus is mainly through contact with contaminated surface or droplet infection (Fig. 1). Patients experienced no symptoms or mild symptoms, like fever, fatigue, dry cough, general malaise, expectoration, headache, diarrhea, nausea, and vomiting, after an incubation period of 14 days (Fig. 2). Severe infections can lead to complications, like pneumonia, organ failure, and death. ${ }^{7,8}$

Infected children are still limited. Compared to infected adults, a mild clinical course is seen. In infected children, fever was most commonly seen. COVID-19 can be identified in infected patients
${ }^{1-4}$ Department of Pediatric and Preventive Dentistry, Kannur Dental College, Kannur, Kerala, India

Corresponding Author: Sruthi Chandran, Department of Pediatric and Preventive Dentistry, Kannur Dental College, Kannur, Kerala, India, Phone: +91 09446770341, e-mail: sruthic27@gmail.com

How to cite this article: Peedikayil FC, Chandran S, Nithya K, et al. Changing Perceptions of Pediatric Dental Practice during COVID Era. J Oral Health Comm Dent 2021;15(2):98-101.

Source of support: Nil

Conflict of interest: None

saliva through three different pathways, i.e., (1) it enters the oral cavity from lower and upper respiratory tract with the liquid droplets, (2) it can enter the mouth from the blood through the crevicular fluid, (3) through salivary duct, by the release of particles in saliva by the infection of salivary gland. ${ }^{4}$ Literature has revealed that coronavirus was affected all children even the mortality rate was low.

Coronavirus disease 2019 infected children show various changes in their blood bank, like leucopenia, lymphopenia, increased lactate dehydrogenase, and erythrocyte sedimentation rate. In addition to these blood changes in the infected children, there will be positive reverse transcription-polymerase chain reaction (RT-PCR) with high viral load, increased levels of

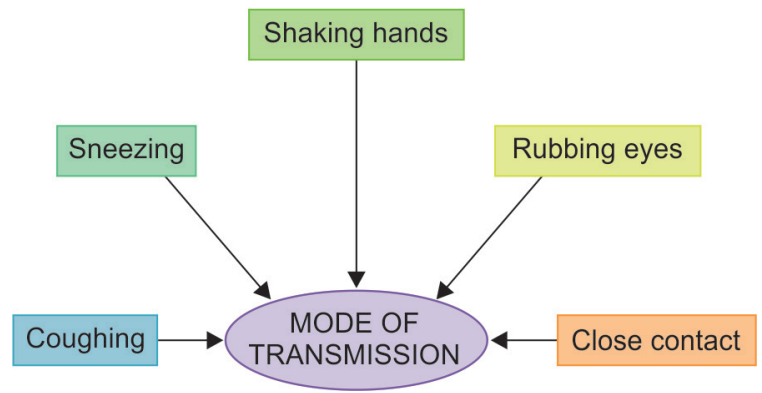

Fig. 1: Mode of transmission

(-) The Author(s). 2021 Open Access This article is distributed under the terms of the Creative Commons Attribution 4.0 International License (https://creativecommons. org/licenses/by-nc/4.0/), which permits unrestricted use, distribution, and non-commercial reproduction in any medium, provided you give appropriate credit to the original author(s) and the source, provide a link to the Creative Commons license, and indicate if changes were made. The Creative Commons Public Domain Dedication waiver (http://creativecommons.org/publicdomain/zero/1.0/) applies to the data made available in this article, unless otherwise stated. 


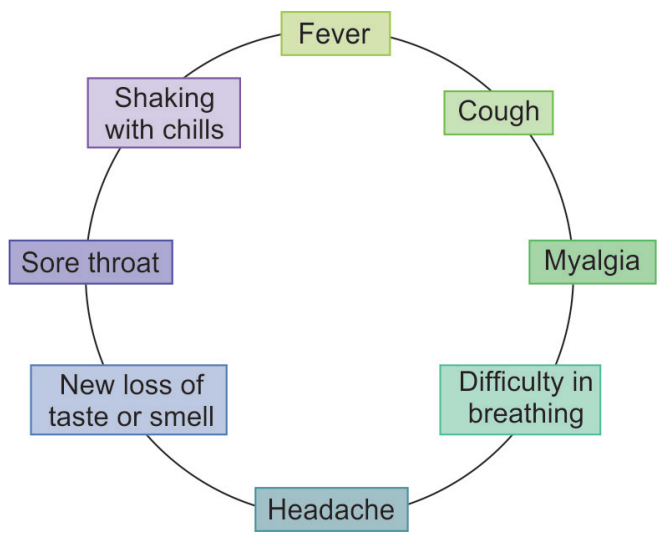

Fig. 2: Common symptoms of COVID-19

procalcitonin, serum transaminase, and muscle enzymes. Chest radiograph shows patchy infiltration with multiple changes.

Current knowledge about the antiviral treatment of COVID-19 is limited and no specific treatment exists. Severe cases require respiratory assistance with organ support in intensive care. Clinical trials using antiviral, antimalarial, and biological drugs are ongoing, and their results will define the best way to treat COVID-19. ${ }^{9}$

\section{Pediatric Dentistry before COVID-19}

Due to the increase in incidence of spreadable diseases, crossinfection measures play an important role in dentistry. These concepts in dental infection control were improved in the 1960s and were carried out after human immune deficiency viral (HIV) infections became an epidemic. ${ }^{10,11}$ Due to high-speed handpieces or ultrasonic scalars are used, an increased amount of microorganism containing aerosols is released into the environment. Hence the skin, environment, and instruments can be contaminated with saliva, blood, or organic debris. There are different barrier techniques that are advised to guard both the dental practitioner as well as the patient from cross-infection during the dental examination and treatments. This includes mouth mask, gloves, protective eye wear, and protective clothing.

In case of pediatric dentistry, children are having varying levels of physical, mental, emotional, and social development. Thus dental practitioner faces more challenges when treating children with sustaining proper infection control practices. ${ }^{12}$ There are different methods in dentistry to manage dental caries infections in pediatric patients. This includes interim therapeutic restoration, the use of silver diamine fluoride (SDF), and the Hall technique. These are helpful to treat carious primary teeth with a minimal need for behavior guidance. Although infection control is an essential part of dental treatment, routine preventive measures have not been applied effectively during the treatment and also some of the barrier measures are not effective in preventing the spread of COVID-19.

\section{Changing Perception of Parents of Child Dental Patients: COVID-19 Era}

Parents act as the primary implementers of children's daily oral care. Half of the parents' conceptions are dental departments were more dangerous than other places. Some of them believed that their children could be easily infected with the virus while receiving dental treatment. Most parents understand the source of the virus infection as droplets and blood but half of them thought it may be a medical apparatus as well as dentists themselves, which indicates that parents have poor trust in the protection measures of the dental clinic and they are worried about the sterilization and disinfection procedures that are carried out in the clinic and also protection measures between dentists and patients. This enlightens to strengthen the propaganda of dental clinic protection work during the outbreak of COVID-19 to let parents know that we can minimize the droplets and blood or aerosols produced in the treatment process and adequately disinfect and sterilize our medical equipment as well as perfect protective measures between dentists and patients. ${ }^{12}$

\section{Dental Considerations for Pediatric Patients during COVid-19 Pandemic Crises}

According to $\mathrm{WHO}$, the pandemic has got six different phases. ${ }^{12}$ Dental procedures, with a large number of droplets and aerosols, have a high potential to transmit microorganisms from an infected individual. In pediatric dentistry, children who are asymptomatic or who produce mild and moderate symptoms are at higher risk with more severe complications compared to adults. ${ }^{4}$

Dental care settings have a high risk of COVID-19 infection and it is due to the specificity of its procedures, like face-to-face communication with patients, exposure to oral fluids, and also the handling of sharp instruments. Pathogenic microorganisms generated from an infected individual through these procedures will remain suspended in the air for longer periods. ${ }^{13,14}$ Compared to adults, the risk of transmission of COVID-19 virus in pediatric patients is more during orthodontic appliance therapy if handling is not carried out with precautions. ${ }^{15}$ Another problem is the use of personal protective equipment by the children during the medical visit is found to be difficult. ${ }^{16}$ However, literature search shows that in the present pandemic, dental care settings have not been a source of spread of infection.

Importance of preventive dentistry in post-COVID-19 era plays a major role in pediatric patients. First of all minimize the chance for exposures like post a sign at the entrance to the dental practice which instructs patients having symptoms of respiratory infection should reschedule their dental appointment and call their physician, ask questions about new onset of respiratory symptoms, take temperature readings, use physical barriers, make sure the personal protective equipment being used is appropriate for the procedures being performed, use a rubber dam to decrease possible exposure to infectious agents, use high-speed evacuation for dental procedures, autoclave handpieces after each patient. Clean and disinfect public areas frequently, including door handles, chairs, and bathrooms. ${ }^{14}$

Prevention against the carious process in children should start from home oral hygiene, such as the use of dental floss after completion of permanent dentition. Advice parents about the importance of incorporating a diet rich in fruits and vegetables, which will protect not only from onset of caries but also from gum disease. During this pandemic time, children are spending much of their time at home which forced them to frequent intake of fermentable carbohydrates as well as soft drinks consumption that will cause later dental erosion and makes enamel tissue less resistant to cariogenic bacteria.

Early childhood caries is the commonly affected disease in children which affects mainly in an age-group of 3-5 years, with a clinical manifestation of early onset of local abscess with painful 
symptoms. Children with these symptoms need emergency intervention. Hence during this period of COVID-19, the chances of children to get exposed to this potential risk are high. The fundamental importance in early childhood caries is the prevention in which oral health plays an important role. ${ }^{16,17}$

Due to the spread of COVID-19, WHO advised that nonessential oral healthcare, such as routine checkups, dental cleanings, and preventive care, must be delayed until there has been sufficient reduction in COVID-19 transmission rate. ${ }^{15}$ Treatments that are at high risk in children are acute pulpitis, dental abscess, dentoalveolar trauma, pain of cavitation needing temporization, and unavoidable dental extractions whereas orthodontic procedures are at moderate risk. ${ }^{14}$ Currently, many professional organizations have recommended only emergency dental care procedures in order to eliminate the spread of COVID-19, but it is unacceptable for a long-term practice. Due to this scenario, American Academy of Pediatric Dentistry (AAPD) proposed a checklist to address significant areas of practice that may need attention.

\section{Clinical Recommendations in COVID-19 ERA}

Post-COVID-19 follow-up protocols include the following:

- Continue use of mask, hand hygiene, and physical distancing.

- Sufficient intake of warm water.

- Practice mild or moderate exercises, like yoga, meditation, and daily walking.

- Have a well-balanced nutritious diet, which is easily digestible.

- Take regular medications as advised for COVID and also for managing comorbidities.

- Self-health monitoring at home.

- Should take steam inhalation and do saline gargle, if there is persistent dry cough or sore throat. The addition of herbs/spices for gargling/steam inhalation and cough medications should be taken on advice of medical doctor or qualified practitioner of Ayush.

- Look for any early warning signs. ${ }^{18}$

Recommendations for treatment include the following: isolate the operating field with the rubber dam, use four-handed dentistry techniques, get parents to leave the operating room, and use a high volume aspirator during the treatment producing aerosols. ${ }^{19,20}$ To avoid contamination, extraoral radiographs are recommended. When intraoral imaging is essential, sensors should be doubly covered to prevent perforation. After the use, it must be correctly disinfected to avoid cross-contamination. Computer-aided design and computer-aided manufacturing (CAD/CAM) dental records are to be used or traditional dental records are to be made of disinfectable synthetic material. ${ }^{21}$

The unpredictability of COVID-19 infection and the diagnosis of symptoms in children present a challenge for all pediatric dentists, which results in increased anxiety for the dental healthcare providers, the parents, and the patients. Through appropriate behavior management technique and enhanced personal protective equipment (PPE) protocol, pediatric dentist can minimize the probability of COVID-19 cross-infection. It is helpful to put this protective equipment on while the child is watching and while we explain to them in simple terms, the value and use of this equipment. Proper coping techniques and communication between the pediatric dentist and the parents and their child are very essential. The AAPD recommends delay in seeing pediatric patients, who are uncooperative, by giving a special hour in the day for treating patients on parent's lap with parents wearing the mask.

\section{Role of Preventive Dentistry in COVID-19 ERA}

Evidence-based strategies are available for caries prevention as well as its management in both primary and permanent dentition. These strategies are more appropriate under the current and near-future circumstances of COVID-19. During this pandemic period, minimal or no aerosol-generating procedures, such as biological atraumatic, noninvasive, or minimally invasive treatment methods, would be safer and give high success rate in caries management. Treatment modalities, like fluoride varnish, and resin infiltration, to arrest noncavitated caries, atraumatic restorative technique, indirect pulp capping, the Hall technique, and the use of SDF might be a treatment alternative for asymptomatic teeth or teeth exhibiting signs of reversible pulpitis. $^{7}$

\section{CONCLUSION}

Through appropriate behavior management, pediatric dentists can minimize the probability of SARS-CoV-2 cross-infection. Proper care along with infection control strategies and newer approaches of management of children have to be incorporated in the pediatric dentistry after COVID-19 period.

\section{References}

1. Mallineni SK, Innes NP, Raggio DP, et al. Coronavirus disease (COVID-19): Characteristics in children and considerations for dentists providing their care. Int J Paediatr Dent 2020;30(3):245-250. DOI: 10.1111/ipd.12653.

2. Saleem H, Rahman J, Aslam N, et al. Coronavirus disease 2019 (COVID-19) in children: Vulnerable or spared? A systematic review. Cureus 2020;12(5):e8207. DOI: 10.7759/cureus.8207.

3. Kumar D, Malviya R, Kumar Sharma P. Corona virus: a review of COVID-19. EJMO 2020;4(1):8-25. DOI: 10.14744/ejmo.2020.51418.

4. Ferrazzano GF, Ingenito A, Cantile T. COVID-19 disease in children: what dentists should know and do to prevent viral spread. The Italian point of view. Int J Environ Res Public Health 2020;17(10):3642. DOI: 10.3390/ijerph17103642.

5. World Health Organization. COVID-19 weekly epidemiological update. Available from: https://www.who.int/emergencies/ diseases/novel-coronavirus-2019/situation-reports. (last accessed on 2 January 2021).

6. Al-Nerabiah Z, Alkhouli M, Laflouf M, et al. Pediatric dentists consideration for Covid-19 in children. Int J Appl Dent Sci 2020; 6(2):628-630. Available from: https://doi.org/10.22271/oral.

7. Al-Halabi M, Salami A, Alnuaimi $E$, et al. Assessment of paediatric dental guidelines and caries management alternatives in the post COVID-19 period. A critical review and clinical recommendations. Eur Arch Paediatr Dent 2020;21(5):543-556. DOI: 10.1007/s40368-02000547-5.

8. Singhal T. A review of coronavirus disease-2019 (COVID-19). Indian J Pediatr 2020;87(4):281-286. DOI: 10.1007/s12098-02003263-6.

9. Bhanushali P, Katge F, Deshpande S, et al. COVID-19: changing trends and its impact on future of dentistry. Int J Dent 2020;2020:8817424. DOI: 10.1155/2020/8817424.

10. Sharma L, Pradhan D, Todkar M, et al. Infection control and dentistry: a review. Int J Oral Health Med Res 2018;5(3):27-29. DOI :101111/ IJOHMR.12331. 
11. Khader Y, Al Nsour M, Al-Batayneh OB, et al. Dentists' awareness, perception, and attitude regarding COVID-19 and infection control: cross-sectional study among Jordanian dentists. JMIR Public Health Surveill 2020;6(2):e18798. DOI: 10.2196/18798.

12. Sun J, Xu Y, Qu Q, et al. Knowledge of and attitudes toward COVID-19 among parents of child dental patients during the outbreak. Braz Oral Res 2020;34:e066. DOI: 10.1590/1807-3107BOR-2020.vol34.0066.

13. World Health Organization pandemic phase descriptions. Available from: http://www.who.int/about/structure/en/index.html. (Last accessed on 12 December 2020).

14. Indian Dental Association. Indian Dental Association's preventive guidelines for dental professionals on the coronavirus threat. Available from: https://www.ida.org.in/pdf/IDA. (Last accessed on 12 January 2021)

15. Amorim LM, Maske TT, Ferreira SH, et al. New post-COVID-19 biosafety protocols in pediatric dentistry. Pesqui Bras Odontopediatria Clín Integr 2020;20 (Suppl. 1). DOI: 10.1590/pboci.2020.117.
16. Luzzi V, lerardo G, Bossù M, et al. COVID-19: pediatric oral health during and after the pandemics. 2020. Int J Paediatr Dent 2021;31(1):20-26. DOI: $10.1111 /$ ipd.12737.

17. World Health Organization. Considerations for the provision of essential oral health services in the context of COVID-19: Interim guidance. World Health Organization; 2020. Available from: https:// apps.who.int/iris/handle/10665/333625.

18. Government of India, Ministry of Health and Family Welfare. Post COVID management protocol.

19. Guidelines for Dental Professionals in Covid-19 pandemic situation.

20. Amato A, Caggiano M, Amato M, et al. Infection control in dental practice during the COVID-19 pandemic. Int J Environ Res Public Health 2020;17(13):4769. DOI: 10.3390/ijerph17134769.

21. Spicciarelli V, Marruganti C, Viviano $M$, et al. Prevention and safety in the dental office after Novel Human Coronavirus outbreak: unresolved questions and future directions. J Osseointegr 2020;12(2):145-153. DOI: 10.23805/JO.2020.12.01.11. 